\title{
Autism Spectrum Disorders and Race, Ethnicity, and Nativity: A Population-Based Study
}

AUTHORS: Tracy A. Becerra, PhD, a Ondine S. von

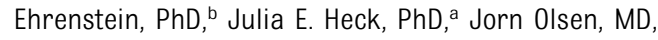
PhD, ${ }^{a}$ Onyebuchi A. Arah, MD, DSc, PhD, a Shafali S. Jeste, MD, ${ }^{\mathrm{c}}$ Michael Rodriguez, MD, ${ }^{\mathrm{d}}$ and Beate Ritz, MD, PhD ${ }^{\mathrm{a}}$

Departments of ${ }^{a}$ Epidemiology, and ${ }^{b}$ Community Health Sciences, Fielding School of Public Health, University of California, Los Angeles, Los Angeles, California; and Departments of ${ }^{C}$ Psychiatry and Behavioral Sciences, and dFamily Medicine, University of California, Los Angeles, Los Angeles, California

\section{KEY WORDS}

autistic disorder, emigration and immigration, epidemiology, continental population groups

\section{ABBREVIATIONS}

$A D$-autistic disorder

ASD—autism spectrum disorder

CDER - Client Development Evaluation Report

DDS-Department of Developmental Services

DSM-IV-R-Diagnostic and Statistical Manual of Mental Disorders, Revised Fourth Edition

DSM-5-Diagnostic and Statistical Manual of Mental Disorders, Fifth Edition

LA-Los Angeles

MR-mental retardation

PI—Pacific Islander

SES-socioeconomic status

Dr Becerra conceptualized and designed the study, carried out the analyses, and drafted the initial manuscript; Dr von Ehrenstein contributed to the conceptualization of the study and critically reviewed and revised the manuscript; Dr Heck critically reviewed and revised the manuscript; Drs Olsen, Arah, Jeste, and Rodriguez provided content and critical feedback on the manuscript; Dr Ritz coordinated, conceptualized, and designed the study, as well as contributed to drafting and editing the manuscript; and all authors approved the final manuscript as submitted.

www.pediatrics.org/cgi/doi/10.1542/peds.2013-3928

doi:10.1542/peds.2013-3928

Accepted for publication Apr 22, 2014

Address correspondence to Beate Ritz, MD PhD, Department of Epidemiology, Fielding School of Public Health; Box 951772, 650 Charles E. Young Dr, Los Angeles, CA 90095-1772. E-mail: britz@ucla.edu PEDIATRICS (ISSN Numbers: Print, 0031-4005; Online, 1098-4275). Copyright (c) 2014 by the American Academy of Pediatrics

(Continued on last page)
(7HAT'S KNOWN ON THIS SUBJECT: Autism prevalence is reported to be highest among non-Hispanic white children, lower in Hispanic and African American/black children, and highly variable in Asian/Pacific Islanders. More comorbid intellectual disability and delays in expressive language have been observed among Hispanic and African American children.

WHAT THIS STUDY ADDS: Maternal nativity is a risk factor for childhood autism in US populations. We observed higher risk of severe autism phenotypes in children of foreign-born black, Central/South American, Filipino, and Vietnamese mothers and US-born African Americans and Hispanics compared with US-born whites.

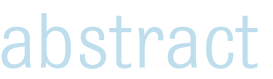

OBJECTIVE: Our understanding of the influence of maternal race/ethnicity and nativity and childhood autistic disorder (AD) in African Americans/ blacks, Asians, and Hispanics in the United States is limited. Phenotypic differences in the presentation of childhood $A D$ in minority groups may indicate etiologic heterogeneity or different thresholds for diagnosis. We investigated whether the risk of developing $A D$ and $A D$ phenotypes differed according to maternal race/ethnicity and nativity.

METHODS: Children born in Los Angeles County with a primary AD diagnosis at ages 3 to 5 years during 1998-2009 were identified and linked to 1995-2006 California birth certificates (7540 children with $A D$ from a cohort of 1626354 births). We identified a subgroup of children with $A D$ and a secondary diagnosis of mental retardation and investigated heterogeneity in language and behavior.

RESULTS: We found increased risks of being diagnosed with $A D$ overall and specifically with comorbid mental retardation in children of foreignborn mothers who were black, Central/South American, Filipino, and Vietnamese, as well as among US-born Hispanic and African American/ black mothers, compared with US-born whites. Children of US African American/black and foreign-born black, foreign-born Central/South American, and US-born Hispanic mothers were at higher risk of exhibiting an $A D$ phenotype with both severe emotional outbursts and impaired expressive language than children of US-born whites.

CONCLUSIONS: Maternal race/ethnicity and nativity are associated with offspring's AD diagnosis and severity. Future studies need to examine factors related to nativity and migration that may play a role in the etiology as well as identification and diagnosis of $A D$ in children. Pediatrics 2014;134:e63-e71 
For 2 decades, autism prevalence has risen in the United States and now reaches $\sim 147$ per 10000 children diagnosed with autism spectrum disorders (ASDs) by 8 years of age and 21 per 10000 children with autistic disorder (AD).1,2 The associated disabilities are characterized by atypical development of socialization and communication and the presence of restricted, repetitive interests and behaviors beginning in early childhood. ${ }^{1,3}$ Lower ASD prevalence in Hispanic and African American/black children (henceforth "black") than in non-Hispanic white children (henceforth "white") and variations in prevalence from 30 to 210 per 10000 among Asians/Pacific Islanders (Asians/PIs) have been reported. 2,4,5 Autism phenotype differences with regard to intellectual and language disabilities across race/ethnic groups in the United States may suggest differences in ASD etiology and disparities in diagnostic and treatment-related factors. ${ }^{4,6-8}$

The prenatal period is strongly implicated in ASD etiology9-11; yet, except for parental age and some pregnancy complications, evidence is insufficient for many potential prenatal risk factors, including recently reported associations with immigration status of the mother. ${ }^{10,12}$ Epidemiology has a long tradition of using migration studies to understand how environmental and genetic factors contribute to disease risk in populations.13,14 The fact that $22 \%$ of children $<6$ years old born in the United States have immigrant parents opens a unique opportunity to consider the influence of nativity and race/ethnicity on the etiology of ASD. ${ }^{15}$

We hypothesized that the prevalence of AD (Diagnostic and Statistical Manual of Mental Disorders, Revised Fourth Edition [DSM- IV-R]) and specific phenotypes, ie, comorbid mental retardation (MR), expressive language, and emotional/ behavioral deficits, differs by maternal race/ethnicity and nativity. We focused our investigation on children born and diagnosed in Los Angeles (LA) County, California, a highly diverse metropolitan region home to black $(400000$ in 2010), ${ }^{16}$ Hispanic (4.7 million in 2009), ${ }^{17}$ and Asian/PI (1.4 million in 2012) ${ }^{18}$ residents with a high proportion of immigrants (30\% in 2011) ${ }^{19}$ and 92 languages spoken by students of the LA Unified School District. ${ }^{20}$ Our findings have clinical implications for early identification and treatment of ASD and research implications that raise innovative hypotheses, not only for different racial/ ethnic groups but specifically for large and diverse immigrant communities who vary in risk, protective factors, and access to health care.

\section{METHODS}

We studied children born to mothers who resided in LA County, California, between 1995 and 2006. Children included in the current study had birth certificate information on maternal race/ethnicity and maternal nativity and a plausible gestational age (21-46 weeks) and birth weight (500-6800 g). Maternal race/ethnicity and nativity were determined on the basis of mother's self-reported Hispanic origin (yes or no), race (non-Hispanic white, non-Hispanic black, Hispanic, and nonHispanic Asian), and maternal nativity (US-born or foreign-born). California birth certificates also asked Hispanic mothers to identify their ethnic ancestry and specified country of origin for several Asian and Latin American nations and US territories. Asian ethnic ancestry for US-born mothers was available, but investigating $A D$ in USborn Asians by country of origin was not possible due to small numbers (138 cases among 21678 births).

In LA County, children needing assessment and treatment of ASD are seen at a network of 7 regional centers contracted by the California Department of Developmental Services (DDS). Referrals to regional centers are made according to residential address by pediatricians, other clinical providers, and schools; parents can also self-refer their children. During our study period, DDS services were available to all children free of charge irrespective of income, type of health insurance, or immigration status. The diagnosis of $A D$ was based on the DSM- IV-R (International Classification of Diseases, Ninth Revision, Clinical Modification [ICD-9-CM] code 299.00), ${ }^{3}$ as reported on the DDS Client Development Evaluation Report (CDER). The AD diagnoses for these children would likely hold under the new ASD diagnostic criteria in the Diagnostic and Statistical Manual of Mental Disorders, Fifth Edition (DSM-5). ${ }^{21}$ Validation studies have established the reliability and validity of the CDER. 22,23

Trained psychologists usually make the diagnostic determination of AD/ASD at 7 DDS regional centers. Best practice suggests that primary care providers provide a comprehensive medical assessment including a health history, physical examination, and developmental/ neurologic examination. California published guidelines in 2002 to establish a comprehensive diagnostic evaluation for ASD that encompasses the following: (1) review of relevant background information, (2) parent/caregiver interview, (3) comprehensive medical evaluation, (4) cognitive assessment, (5) measures of adaptive functioning, and (6) direct observation, in which the $\mathrm{Au}$ tism Diagnostic Observation Scale was 1 recommended tool. ${ }^{24}$

From DDS records, we identified 10821 children with a primary AD diagnosis at 36 to 71 months of age during 19982009 and were able to link 8600 (79.5\%) to a California birth record by using a probabilistic linkage program, as described in a previous article. ${ }^{25,26}$ The main reason for nonlinkage of 2221 DDS records was missing/incomplete information on the birth or DDS records. ${ }^{26}$ 
In total, 1626354 births of which 7540 children had an AD diagnosis were eligible according to our criteria and had a mother of white, black, Hispanic, or Asian/PI race/ethnicity.

We also identified a subgroup of children with $A D$ and a secondary diagnosis of MR (AD-MR), according to DSM-IV terminology from the CDER (ICD-9-CM codes: 317 , mild; 318.0 , moderate; 318.1, severe; 318.2, profound; 319, MR unspecified). Although we will use the term "mental retardation" in the context of the actual diagnoses, we recognize the changes in terminology to "intellectual disability" in the DSM-5 and will refer to the more accepted term when speaking more broadly. ${ }^{27}$ Although cognitive assessment methods were not described explicitly on the CDER, standard and informal procedures are recommended to assess both verbal and nonverbal cognitive functioning. ${ }^{24}$ To investigate heterogeneity in phenotype for language and behavior, we restricted our data to 5 -year-olds, limiting variation due to age-dependent development $(n=1340$ 850). From DDS evaluation records, we identified 4 subgroups with overlap between language and behavior subtypes, measured by caregiver interview, observation, or demonstration 23 : 2 subgroups with either "impaired" or "less impaired" expressive language (AD-impaired expressive language: child does not use words, says simple words or 2-word sentences; AD-lessimpaired expressive language: child uses sentences of $\geq 3$ words or at least can engage in basic conversation) and 2 subgroups with "severe" or "less severe" emotional outburst behavior (AD-severe outbursts: child has daily or weekly tantrums requiring restraint; AD-less-severe outburst: child has no tantrums or weekly or less than weekly tantrums without needing restraint). This research was approved by the University of California Los Angeles and the California Committee for the Protection of Human Subjects.

In unconditional logistic regression models we estimated crude and adjusted odds ratios and $95 \%$ confidence intervals and report relative risks for the following outcomes: AD, AD-MR, AD-impaired expressive language, AD-lessimpaired expressive language, AD-severe outbursts, and AD-less-severe outbursts according to maternal race/ethnicity and nativity with US-born white mothers as the reference.

To examine the influence of $A D$ risk factors likely to vary between race/ ethnic groups and by nativity, we present several adjusted models. Our purpose was to quantify associations while adjusting for multiple factors, although some risk factors may be on the causal pathway(s) between race/ ethnicity/nativity and AD. First, we adjusted for maternal age, the strongest known risk factor. ${ }^{10}$ We did not adjust for paternal age due to a high percentage of missing information, especially for children of black mothers (19\%). Among those with information available, the correlation between mother's and father's age was strong $(r=0.73)$. Second, we additionally adjusted for child's gender, birth year, type of birth, parity, gestational age, birth weight, the trimester that prenatal care began, and pregnancy complications. Third, we adjusted for maternal education and insurance type, which was previously observed to be a reasonable indicator of socioeconomic status (SES). ${ }^{28}$ Finally, to consider possible diagnostic variability, we controlled for DDS regional center catchment area (for controls, regional center was according to residential address during birth).

\section{RESULTS}

The mean age of children entering the DDS system differed by no more than 6 months by maternal race/ethnicity and nativity (range: 3 years 1 month to 3 years 7 months); children identified earliest were born to US-born Asian, foreign-born Japanese, foreign-born black, and US-born white mothers, whereas those diagnosed later were children of mothers who immigrated from Central/South America and Vietnam.

Crude rates of being diagnosed with $A D$ varied by race/ethnicity and nativity (from 32 to 93 per 10000 births), and fully adjusted risks were $76 \%$ higher in children of foreign-born black mothers, $43 \%$ higher in foreign-born Vietnamese, $25 \%$ higher in foreign-born Filipinos, 26\% higher in foreign-born Central/South Americans, and $13 \%$ to $14 \%$ higher in US-born Hispanics and blacks compared with US-born white mothers (Table 1). Children whose mothers were born in China and Japan were at $\sim 30 \%$ lower risk of $A D$ compared with white US-born children, and adjustment for all available risk factors changed estimates only minimally. Additional adjustment for regional center changed the risk of $A D$ only for children of US-born black mothers in a substantive manner and suggested an increased risk.

\section{AD-MR}

Among 806 children diagnosed with AD-MR (Table 2), the highest crude rates were observed in children of foreign-born black, Vietnamese, and Filipino mothers. Adjustment for other risk factors strengthened estimates with more than twofold increased risks compared with whites. For all children, adjusted risk estimates were $>1$ (95\% confidence intervals included the null values for smaller groups), regardless of maternal nativity, except for Mexicanborn mothers.

AD: Expressive Language Skills and Emotional Outburst Phenotypes

For 5-year old children with impaired AD expressive language abilities (Table 3 ), 
TABLE 1 Maternal Race/Ethnicity and Nativity in Relation to Children's Diagnosis of AD in LA County

\begin{tabular}{|c|c|c|c|c|c|c|c|c|}
\hline $\begin{array}{c}\text { Maternal } \\
\text { Race/Ethnicity } \\
\text { and Nativity }\end{array}$ & $\begin{array}{l}\text { Mean (SD) Age } \\
\text { at Diagnosis, y }\end{array}$ & $\begin{array}{c}\text { Case/Cohort, } \\
n\end{array}$ & $\begin{array}{c}\text { Rate, per } \\
10000 \text { Births }\end{array}$ & $\begin{array}{l}\text { Crude RR } \\
(95 \% \mathrm{Cl})\end{array}$ & $\begin{array}{l}\text { Maternal Age- } \\
\text { Adjusted RR } \\
(95 \% \mathrm{Cl})\end{array}$ & $\begin{array}{l}\text { Adjusted RR }{ }^{\mathrm{a}} \\
\qquad(95 \% \mathrm{Cl})\end{array}$ & $\begin{array}{l}\text { Additionally Adjusted } \\
\qquad \operatorname{RR}^{\mathrm{b}}(95 \% \mathrm{Cl})\end{array}$ & $\begin{array}{l}\text { RR Additionally } \\
\text { Adjusted by Regional } \\
\text { Center }(95 \% \mathrm{Cl})\end{array}$ \\
\hline \multicolumn{9}{|l|}{ White } \\
\hline US-born & $3.4(0.9)$ & $1477 / 236347$ & 62.5 & 1.00 & 1.00 & 1.00 & 1.00 & 1.00 \\
\hline Foreign-born & $3.3(0.9)$ & $420 / 63464$ & 66.2 & $1.06(0.95-1.18)$ & $1.06(0.95-1.19)$ & $1.02(0.91-1.14)$ & $1.05(0.94-1.17)$ & $1.04(0.93-1.16)$ \\
\hline \multicolumn{9}{|l|}{ Black } \\
\hline US-born & $3.4(0.9)$ & $526 / 123316$ & 42.6 & $0.68(0.62-0.75)$ & $0.84(0.76-0.93)$ & $1.00(0.90-1.10)$ & $1.04(0.94-1.15)$ & $1.14(1.02-1.26)$ \\
\hline Foreign-born & $3.2(0.9)$ & $92 / 10093$ & 91.2 & $1.46(1.18-1.80)$ & $1.49(1.20-1.84)$ & $1.59(1.28-1.96)$ & $1.65(1.33-2.05)$ & $1.76(1.41-2.18)$ \\
\hline \multicolumn{9}{|l|}{ Hispanic } \\
\hline US-born & $3.5(0.8)$ & $1376 / 316565$ & 43.5 & $0.70(0.65-0.75)$ & $0.97(0.90-1.05)$ & $1.08(1.00-1.17)$ & $1.15(1.06-1.24)$ & $1.13(1.04-1.22)$ \\
\hline Foreign-born & $3.5(0.9)$ & $2594 / 711825$ & 36.4 & $0.58(0.55-0.62)$ & $0.69(0.64-0.73)$ & $0.85(0.79-0.91)$ & $1.05(0.97-1.14)$ & $1.06(0.98-1.15)$ \\
\hline Mexico & $3.5(0.9)$ & $1792 / 548977$ & 32.6 & $0.52(0.49-0.56)$ & $0.61(0.57-0.66)$ & $0.76(0.70-0.82)$ & $0.95(0.86-1.05)$ & $0.95(0.86-1.05)$ \\
\hline $\begin{array}{l}\text { Central/South } \\
\text { America }\end{array}$ & $3.6(0.9)$ & $760 / 157147$ & 48.4 & $0.77(0.71-0.84)$ & $0.89(0.81-0.97)$ & $1.08(0.98-1.19)$ & $1.25(1.13-1.39)$ & $1.26(1.14-1.40)$ \\
\hline \multicolumn{9}{|l|}{ Asian/PI } \\
\hline US-born & $3.1(0.8)$ & $138 / 21678$ & 63.7 & $1.02(0.85-1.21)$ & $1.08(0.91-1.29)$ & $1.03(0.86-1.22)$ & $1.02(0.85-1.21)$ & $1.04(0.87-1.24)$ \\
\hline Foreign-born & $3.5(0.9)$ & $917 / 143066$ & 64.1 & $1.03(0.94-1.11)$ & $1.01(0.93-1.10)$ & $0.98(0.90-1.06)$ & $1.04(0.95-1.13)$ & $1.02(0.93-1.11)$ \\
\hline China & $3.5(0.9)$ & $145 / 29666$ & 48.9 & $0.78(0.66-0.93)$ & $0.74(0.62-0.87)$ & $0.66(0.56-0.79)$ & $0.74(0.62-0.89)$ & $0.69(0.57-0.83)$ \\
\hline Japan & $3.2(0.7)$ & 29/5815 & 49.9 & $0.82(0.57-1.18)$ & $0.76(0.53-1.09)$ & $0.71(0.49-1.02)$ & $0.72(0.50-1.04)$ & $0.70(0.48-1.03)$ \\
\hline Korea & $3.4(0.9)$ & 136/22 206 & 61.2 & $0.98(0.82-1.16)$ & $0.98(0.82-1.18)$ & $0.92(0.77-1.10)$ & $0.95(0.80-1.14)$ & $0.97(0.81-1.17)$ \\
\hline Philippines & $3.5(1.0)$ & $266 / 35306$ & 75.3 & $1.21(1.06-1.37)$ & $1.21(1.06-1.37)$ & $1.23(1.08-1.40)$ & $1.23(1.08-1.41)$ & $1.25(1.09-1.43)$ \\
\hline Vietnam & $3.6(0.9)$ & $179 / 19287$ & 92.8 & $1.48(1.27-1.74)$ & $1.49(1.27-1.74)$ & $1.45(1.24-1.70)$ & $1.58(1.35-1.86)$ & $1.43(1.21-1.68)$ \\
\hline
\end{tabular}

$\mathrm{Cl}$, confidence interval; RR, risk ratio.

a Adjusted for maternal age ( $\leq 18,19-25,26-30,31-35$, or $>35$ years), type of birth (single or twin+), parity (1, 2, 3, or $>3$ children), infant gender (male or female), year of birth (1995-2006), gestational age ( $<37$ weeks or $\geq 37$ weeks), birth weight ( $<2500,2500-4500$, or $>4500$ g), trimester start of prenatal care (no care, first, second, or third trimester), and any pregnancy complication (hypertension, renal, lung, or cardiac disease, asthma, pyelonephritis, diabetes, gestational diabetes, Rh sensitivity, hemoglobinopathy, uterine bleeding, hydramnios, incomplete cervix, sexually transmitted diseases, hepatitis B, rubella, other infections, prenatal tobacco use, and large fibroids).

${ }^{\mathrm{b}}$ Additionally adjusted for maternal education (less than high school, high school, more than high school) and insurance type (Medi-Cal, private insurance, other).

most race/ethnicity and nativity subgroups were at higher risk of an impaired expressive language phenotype, which persisted when restricting to children who were diagnosed early (ie, at 2 or 3 years of age; results not shown). Fewer differences for children with a less impaired language phenotype were observed (ie, risks were comparable to US-born whites, except for children of foreign-born Mexican, Chinese, and Korean mothers who were at lower risk).

Considering the 1396 with a "severe" emotional outburst behavior phenotype among 4197 total 5-year-old children with $A D$, those born to US-born Hispanic and foreign-born Central/ South American mothers were at higher risk only in the severe outburst category (Table 4). However, higher risk of severe outbursts only persisted in conjunction with impaired expressive language (results not shown). Children of foreign-born black mothers were at increased risk of both phenotypes, whereas Vietnamese and Filipino offspring exhibited slightly higher risks of $A D$ with the less severe outburst phenotype.

\section{DISCUSSION}

We investigated the influence of maternal race/ethnicity and nativity on $A D$ diagnosis in LA County, a racially diverse area with a high percentage of recent immigrants. We found compelling evidence that, compared with children born to white US-born mothers, children of foreign-born black, Filipino, and Vietnamese mothers had higher risks of developing or being diagnosed with $A D$, specifically with $M R$ and impaired expressive language. Previously, immigration status was reported to not be associated with high risk of $A D$ in California, ${ }^{5}$ possibly due to the lower risks we observed among offspring of foreign-born Mexican women, who make up the majority of the foreign- born population in California (53\%). ${ }^{19}$ However, we found foreign-born black mothers to be at highest risk of having a child with $A D$ and $A D-M R$ and impaired language abilities, consistent with findings of a higher autism risk among children born to refugee mothers from Africa and the Caribbean living in the United Kingdom and Sweden.29-32 Differences in AD risk by race/ethnicity and nativity could imply variation in etiologic factors across racial/ethnic/nativity groups, which might affect fetal or early childhood development, including stress, diet, toxic environmental exposures, or infections. ${ }^{33,34}$ These differences could also point to disparities in accessing and receiving appropriate diagnosis and treatment.

US minority groups are historically believed to be underidentified for ASD, and it is possible that children with milder symptoms did not go to a regional center and were missed during our study period. ${ }^{1,45}$ This view is supported 
TABLE 2 Maternal Race/Ethnicity and Nativity in Relation to Children's Diagnosis of AD-MR

\begin{tabular}{|c|c|c|c|c|c|c|c|c|}
\hline $\begin{array}{l}\text { Maternal Race/Ethnicity } \\
\text { and Nativity }\end{array}$ & $\begin{array}{l}\text { Mean (SD) Age } \\
\text { at Diagnosis, y }\end{array}$ & $\begin{array}{c}\text { Case/Cohort, } \\
n\end{array}$ & $\begin{array}{c}\text { Rate, per } \\
10000 \\
\text { Births }\end{array}$ & $\begin{array}{l}\text { Crude RR } \\
(95 \% \mathrm{Cl})\end{array}$ & $\begin{array}{l}\text { Maternal Age- } \\
\text { Adjusted } \\
\text { RR }(95 \% \mathrm{CI})\end{array}$ & $\begin{array}{l}\text { Adjusted } \mathrm{RR}^{\mathrm{a}} \\
\qquad(95 \% \mathrm{Cl})\end{array}$ & $\begin{array}{l}\text { Additionally } \\
\text { Adjusted } \\
\operatorname{RR}^{\mathrm{b}}(95 \% \mathrm{Cl})\end{array}$ & $\begin{array}{l}\text { RR Additionally } \\
\text { Adjusted by Regional } \\
\text { Center ( } 95 \% \mathrm{Cl})\end{array}$ \\
\hline \multicolumn{9}{|l|}{ White } \\
\hline US-born & $3.2(0.8)$ & $122 / 236347$ & 5.2 & 1.00 & 1.00 & 1.00 & 1.00 & 1.00 \\
\hline Foreign-born & $3.6(1.1)$ & $35 / 63464$ & 5.5 & $1.07(0.73-1.56)$ & $1.06(0.73-1.54)$ & $1.06(0.73-1.55)$ & $1.08(0.74-1.57)$ & $1.20(0.82-1.75)$ \\
\hline \multicolumn{9}{|l|}{ Black } \\
\hline US-born & $3.6(1.0)$ & $78 / 123316$ & 6.3 & $1.23(0.92-1.63)$ & $1.38(1.04-1.84)$ & $1.42(1.06-1.90)$ & $1.47(1.09-1.97)$ & $1.52(1.11-2.06)$ \\
\hline Foreign-born & $3.4(0.9)$ & $13 / 10093$ & 12.9 & $2.49(1.41-4.42)$ & $2.50(1.41-4.42)$ & $2.56(1.44-4.53)$ & $2.67(1.50-4.74)$ & $2.63(1.44-4.78)$ \\
\hline \multicolumn{9}{|c|}{ 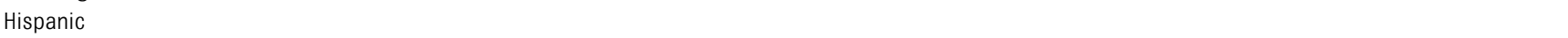 } \\
\hline US-born & $3.6(0.9)$ & $161 / 316565$ & 5.1 & $0.99(0.78-1.25)$ & $1.20(0.94-1.53)$ & $1.30(1.02-1.66)$ & $1.35(1.04-1.73)$ & $1.53(1.18-1.98)$ \\
\hline Foreign-born & $3.6(0.9)$ & $281 / 711825$ & 3.9 & $0.76(0.62-0.95)$ & $0.83(0.67-1.03)$ & $0.91(0.73-1.14)$ & $1.01(0.79-1.30)$ & $1.16(0.90-1.50)$ \\
\hline Mexico & $3.6(0.9)$ & $190 / 548977$ & 3.5 & $0.67(0.53-0.84)$ & $0.71(0.56-0.89)$ & $0.79(0.62-1.01)$ & $0.94(0.70-1.26)$ & $1.04(0.77-1.41)$ \\
\hline Central/South America & $3.7(0.9)$ & $86 / 157147$ & 5.5 & $1.06(0.80-1.40)$ & $1.11(0.84-1.46)$ & $1.20(0.90-1.60)$ & $1.42(1.03-1.96)$ & $1.66(1.20-2.28)$ \\
\hline \multicolumn{9}{|c|}{ Asian/PI } \\
\hline US-born & $3.6(1.1)$ & $14 / 21678$ & 6.5 & $1.25(0.72-2.18)$ & $1.30(0.75-2.26)$ & $1.31(0.75-2.27)$ & $1.30(0.75-2.27)$ & $1.48(0.85-2.58)$ \\
\hline Foreign-born & $3.6(0.9)$ & $102 / 143066$ & 7.1 & $1.38(1.06-1.80)$ & $1.35(1.04-1.76)$ & $1.36(1.04-1.77)$ & $1.41(1.08-1.84)$ & $1.66(1.26-2.18)$ \\
\hline China & $3.6(1.0)$ & 19/29 666 & 6.4 & $1.24(0.76-2.01)$ & $1.19(0.74-1.94)$ & $1.19(0.73-1.93)$ & $1.25(0.76-2.05)$ & $1.40(0.84-2.35)$ \\
\hline Japan & $3.7(0.3)$ & 2/5815 & 3.4 & $0.67(0.16-2.69)$ & NA & NA & NA & NA \\
\hline Korea & $3.0(0.5)$ & 6/22 206 & 2.7 & $0.52(0.23-1.19)$ & NA & NA & NA & NA \\
\hline Philippines & $3.8(1.0)$ & $35 / 35306$ & 9.9 & $1.92(1.32-2.80)$ & $1.90(1.31-2.77)$ & $1.92(1.31-2.80)$ & $1.98(1.36-2.90)$ & $2.27(1.54-3.34)$ \\
\hline Vietnam & $3.6(0.9)$ & $20 / 19287$ & 10.4 & $2.01(1.25-3.22)$ & $1.96(1.22-3.15)$ & $1.96(1.22-3.16)$ & $2.07(1.28-3.35)$ & $2.45(1.50-4.01)$ \\
\hline
\end{tabular}

$\mathrm{Cl}$, confidence interval; NA, not applicable; RR, risk ratio.

a Adjusted for maternal age ( $\leq 18,19-25,26-30,31-35$, or $>35$ years), type of birth (single or twin+), parity (1, 2, 3, or $>3$ children), infant gender (male or female), year of birth (1995-2006), gestational age ( $<37$ weeks or $\geq 37$ weeks), birth weight $(<2500,2500-4500$, or $>4500$ g), trimester start of prenatal care (no care, first, second, or third trimester), and any pregnancy complication (hypertension, renal, lung, or cardiac disease, asthma, pyelonephritis, diabetes, gestational diabetes, Rh sensitivity, hemoglobinopathy, uterine bleeding, hydramnios, incomplete cervix, sexually transmitted diseases, hepatitis B, rubella, other infections, prenatal tobacco use, and large fibroids).

${ }^{\mathrm{b}}$ Additionally adjusted for maternal education (less than high school, high school, more than high school) and insurance type (Medi-Cal, private insurance, other).

by our finding that crude rates of $A D$ in US-born Hispanics and black children were lower than in whites. However, when we assessed maternal race/ ethnicity subgroups by nativity and adjusted for well-known risk factors such as maternal age, similar or higher $A D$ risks were estimated. SES and location of diagnosis may be related to environmental risk factors and may also be a source of identification and diagnosis variability. Adjustment for these factors changed a no-risk to a higher-risk estimate for US-born blacks and a lower risk to a no-risk estimate for children of Mexican-born mothers. Thus, ascertainment bias is possible, and improved early identification is needed in these 2 groups. Ascertainment bias is also supported by the observation that for more severe $A D$ phenotypes that are more likely to prompt identification and treatment, such as the AD-MR and impaired language phenotypes of $A D$, the crude rates were indeed similar in US-born Hispanic, black, and white children but higher after adjustment for risk factors. Language and cultural barriers (ie, low access to psychologists from minority groups, appropriately standardized and language-sensitive assessment instruments) ${ }^{35-38}$ could also have caused underascertainment of $A D$ or misclassification of language skills, a category in which children from all minority groups were at higher risk compared with those with US-born white mothers. Underutilization of formal health services was reported in Chinese and other Asian populations, and underdiagnosis of milder forms of $A D$ at a young age was reported in black children.8,39-41

Information about $\mathrm{AD}$ incidence or prevalence in lower income countries in Africa, ${ }^{42}$ Latin America, and South East $A$ sia $^{43}$ is limited, although rates of ASD are reportedly increasing in Vietnam, ${ }^{44}$ making it difficult to determine whether the observed $A D$ risk reflects rates from country of origin or if it is a migratory phenomenon. Voluntary migration involves physical relocation and is often preceded by uncertainty, with refugees sometimes facing life-threatening situations; after arriving, immigrants may end up in low-SES neighborhoods, becoming socially vulnerable. Women from Central American nations (Guatemala, El Salvador) who migrated seeking asylum in the 1980s may have a history of trauma from civil war, violence, and displacement. ${ }^{45-47}$ Maternal life event stress and psychiatric disorders, possibly related to experiences of escaping wars and disasters, as well as nutritional deficiencies from famine, may be possible explanations for the increased risks observed in Central American, Vietnamese, and some African immigrant groups, ${ }^{48-53}$ and are considered risk factors for lowfunctioning autism in offspring. ${ }^{54,55}$ Dietary factors such as folic acid and vitamin D deficiencies, common among US black and Hispanic women ${ }^{56,57}$ and in women from Vietnam and the Philippines, 58,59 could explain some of the increased risk of $A D$ and AD-MR. ${ }^{60-63}$ In comparison, folic acid 
TABLE 3 Maternal Race/Ethnicity and Nativity in Relation to Child's Diagnosis of AD by Expressive Language Skills at 5 Years of Age

\begin{tabular}{|c|c|c|c|c|c|c|c|c|}
\hline \multirow{2}{*}{$\begin{array}{l}\text { Maternal Race/Ethnicity } \\
\text { and Nativity }\end{array}$} & \multicolumn{4}{|c|}{ Impaired Expressive Language } & \multicolumn{4}{|c|}{ Less-Impaired Expressive Language } \\
\hline & Case/Cohort, $n$ & $\begin{array}{l}\text { Rate, per } \\
10000 \text { Births }\end{array}$ & $\begin{array}{l}\text { Crude RR } \\
(95 \% \mathrm{Cl})\end{array}$ & $\begin{array}{l}\text { Adjusted } \mathrm{RR}^{\mathrm{a}} \\
\quad(95 \% \mathrm{Cl})\end{array}$ & Case/Cohort, $n$ & $\begin{array}{l}\text { Rate, per } \\
10000 \text { Births }\end{array}$ & $\begin{array}{l}\text { Crude RR } \\
(95 \% \mathrm{Cl})\end{array}$ & $\begin{array}{l}\text { Adjusted } \mathrm{RR}^{\mathrm{a}} \\
\quad(95 \% \mathrm{Cl})\end{array}$ \\
\hline \multicolumn{9}{|l|}{ White } \\
\hline US-born & 349/197992 & 17.6 & 1.00 & 1.00 & 509/197992 & 25.7 & 1.00 & 1.00 \\
\hline Foreign-born & 109/51540 & 21.1 & $1.16(0.94-1.44)$ & $1.24(1.00-1.54)$ & $117 / 51540$ & 22.7 & $0.88(0.72-1.08)$ & $0.91(0.74-1.11)$ \\
\hline \multicolumn{9}{|l|}{ Black } \\
\hline US-born & $189 / 103643$ & 18.2 & $1.04(0.87-1.24)$ & $1.37(1.13-1.66)$ & $106 / 103643$ & 10.2 & $0.40(0.32-0.49)$ & $0.84(0.68-1.05)$ \\
\hline Foreign-born & $38 / 8331$ & 45.6 & $2.55(1.83-3.57)$ & $2.76(1.96-3.89)$ & $14 / 8331$ & 16.8 & $0.65(0.38-1.11)$ & $0.90(0.53-1.54)$ \\
\hline \multicolumn{9}{|l|}{ Hispanic } \\
\hline US-born & $429 / 250825$ & 17.1 & $0.92(0.80-1.06)$ & $1.28(1.09-1.49)$ & $309 / 250825$ & 12.3 & $0.48(0.42-0.55)$ & $1.01(0.86-1.19)$ \\
\hline Foreign-born & $993 / 595680$ & 16.7 & $0.95(0.84-1.07)$ & $1.36(1.17-1.57)$ & $451 / 595680$ & 7.6 & $0.30(0.26-0.33)$ & $0.83(0.71-0.97)$ \\
\hline Mexico & $700 / 460141$ & 15.2 & $0.86(076-0.98)$ & $1.12(0.95-1.33)$ & $301 / 460141$ & 6.5 & $0.25(0.22-0.29)$ & $0.78(0.64-0.95)$ \\
\hline $\begin{array}{c}\text { Central/South } \\
\text { America }\end{array}$ & $275 / 130579$ & 21.1 & $1.18(1.01-1.39)$ & $1.57(1.31-1.89)$ & $142 / 130579$ & 10.9 & $0.42(0.35-0.51)$ & $1.03(0.84-1.28)$ \\
\hline \multicolumn{9}{|l|}{ Asian/PI } \\
\hline US-born & $42 / 16886$ & 24.9 & $1.31(0.95-1.81)$ & $1.34(0.97-1.86)$ & $42 / 16886$ & 24.9 & $0.97(0.71-1.33)$ & $1.01(0.74-1.39)$ \\
\hline Foreign-born & $348 / 115953$ & 30.0 & $1.65(1.42-1.91)$ & $1.58(1.35-1.84)$ & $182 / 115953$ & 15.7 & $0.61(0.51-0.72)$ & $0.66(0.55-0.79)$ \\
\hline China & $56 / 23536$ & 23.8 & $1.28(0.96-1.70)$ & $1.06(0.78-1.42)$ & 38/23 536 & 16.1 & $0.63(0.45-0.87)$ & $0.61(0.43-0.87)$ \\
\hline Japan & $13 / 4646$ & 28.0 & $1.51(0.87-2.63)$ & $1.34(0.75-2.40)$ & $5 / 4646$ & 10.8 & $0.42(0.17-1.01)$ & NA \\
\hline Korea & $54 / 17766$ & 30.4 & $1.65(1.24-2.19)$ & $1.82(1.34-2.43)$ & $20 / 17766$ & 11.3 & $0.44(0.28-0.68)$ & $0.52(0.33-0.81)$ \\
\hline Philippines & $94 / 28901$ & 32.5 & $1.80(1.43-2.26)$ & $1.86(1.48-2.34)$ & $55 / 28901$ & 19.0 & $0.74(0.56-0.98)$ & $0.82(0.62-1.10)$ \\
\hline Vietnam & 73/16 070 & 45.4 & $2.56(1.99-3.30)$ & $2.06(1.58-2.70)$ & $34 / 16070$ & 21.1 & $0.82(0.58-1.16)$ & $0.96(0.67-1.37)$ \\
\hline
\end{tabular}

$\mathrm{Cl}$, confidence interval; NA, not applicable; RR, risk ratio.

a Adjusted for maternal age ( $\leq 18,19-25,26-30,31-35$, or $>35$ years), type of birth (single or twin+), parity (1, 2, 3, or $>3$ children), infant gender (male or female), year of birth (1995-2006), gestational age ( $<37$ weeks or $\geq 37$ weeks), birth weight ( $<2500,2500-4500$, or $>4500$ g), trimester start of prenatal care (no care, first, second, or third trimester), any pregnancy complication (hypertension, renal, lung, or cardiac disease, asthma, pyelonephritis, diabetes, gestational diabetes, Rh sensitivity, hemoglobinopathy, uterine bleeding, hydramnios, incomplete cervix, sexually transmitted diseases, hepatitis B, rubella, other infections, prenatal tobacco use, and large fibroids), maternal education (less than high school, high school, more than high school), insurance type (Medi-Cal, private insurance, other), and regional center. Language information is presented for cases 5 years of age at evaluation; cohort is for 1995-2004 births, $N=1340850$

deficiency in pregnant women is less common in China's southern regions, from where a majority of US Chinese immigrants originate. ${ }^{64,65}$ Also, being born and raised in a foreign country may result in less immunity against local host country pathogens, increasing susceptibility to infections common in the United States. Maternal infections can affect fetal brain development, and some authors suggested that influenza and prolonged episodes of fever increase ASD risk. ${ }^{10,66-68}$ This hypothesis may apply to Filipino mothers, of whom a large proportion (30\%) are employed in health care-related occupations in which the risk of exposure to infections is high.69 Studying this common infection hypothesis in more depth, however, is necessary.

Contrary to Central/South American immigrants, children born to immigrant Mexican women were at similar risk to US-born whites for AD and AD-MR.
These children were also at lower risk of being diagnosed with "less impaired" language, possibly suggesting underdiagnosis of milder forms of AD. Alternatively, $A D$ differences favoring Mexican immigrants compared with US-born Hispanic Americans, despite similarly lower income and education, resemble the "Latina paradox" of healthier birth outcomes. ${ }^{70-72}$ Evidence for a Latina paradox is supported by a higher adjusted risk of AD diagnosis among US-born Hispanics, who also had higher risks of more severe phenotypes, including MR, impaired language, and severe emotional outburst behaviors as also seen in an earlier report. ${ }^{73}$

Although the large and diverse LA population allowed us to assess $A D$ risk in offspring of mothers who migrated from different regions of the world, a comparison with US-born women from the same backgrounds was limited due to smaller subgroup sample size. Because the comparison group was US-born white women, differences in prevalence may also be due to genetic variation according to race/ethnicity. The DDS counts of persons with autism likely underestimate the actual California population because it is estimated that $75 \%$ to $80 \%$ of the total population of persons in California with autism are enrolled in the developmental service system. ${ }^{74}$

Although our large sample size did not allow us to validate diagnoses, the diagnostic stability of $A D$ is considered good within the studied age group (the diagnostic consistency for ASD between ages 2 and 9 years is 90\%).22,75 Furthermore, our study included children with a diagnosis of $A D$, which is more likely to hold under DSM-5 criteria (sensitivity: 0.76) than other ASD groups (ie, Asperger syndrome; pervasive developmental disorder, not otherwise specified) (sensitivity: 0.25-0.28). ${ }^{21}$ 
TABLE 4 Maternal Race/Ethnicity and Nativity in Relation to Child's Diagnosis of AD With Severe or Less-Severe Emotional Outburst Behavior at 5 Years of Age

\begin{tabular}{|c|c|c|c|c|c|c|c|c|}
\hline \multirow{2}{*}{$\begin{array}{l}\text { Maternal Race/Ethnicity } \\
\text { and Nativity }\end{array}$} & \multicolumn{4}{|c|}{ Severe Emotional Outbursts } & \multicolumn{4}{|c|}{ Less-Severe Emotional Outbursts } \\
\hline & Case/Cohort, $n$ & $\begin{array}{c}\text { Rate, per } \\
10000 \text { Births }\end{array}$ & $\begin{array}{l}\text { Crude RR } \\
(95 \% \mathrm{Cl})\end{array}$ & $\begin{array}{l}\text { Adjusted } \mathrm{RR}^{\mathrm{a}} \\
\quad(95 \% \mathrm{Cl})\end{array}$ & Case/Cohort, $n$ & $\begin{array}{c}\text { Rate, per } \\
10000 \text { Births }\end{array}$ & $\begin{array}{l}\text { Crude RR } \\
(95 \% \mathrm{Cl})\end{array}$ & $\begin{array}{l}\text { Adjusted } \mathrm{RR}^{\mathrm{a}} \\
\qquad(95 \% \mathrm{Cl})\end{array}$ \\
\hline \multicolumn{9}{|l|}{ White } \\
\hline US-born & 272/197992 & 13.7 & 1.00 & 1.00 & 586/197992 & 29.6 & 1.00 & 1.00 \\
\hline Foreign-born & $66 / 51540$ & 12.8 & $0.93(0.71-1.22)$ & $0.98(0.74-1.28)$ & $154 / 51540$ & 29.9 & $0.98(0.82-1.17)$ & $1.04(0.87-1.24)$ \\
\hline \multicolumn{9}{|l|}{ Black } \\
\hline US-born & 84/103 643 & 8.1 & $0.59(0.46-0.75)$ & $0.93(0.72-1.20)$ & 209/103 643 & 20.2 & $0.68(0.58-0.80)$ & $1.10(0.93-1.31)$ \\
\hline Foreign-born & $17 / 8331$ & 20.4 & $1.49(0.91-2.43)$ & $1.72(1.03-2.86)$ & $34 / 8331$ & 40.8 & $1.38(0.96-1.92)$ & $1.63(1.15-2.31)$ \\
\hline \multicolumn{9}{|l|}{ Hispanic } \\
\hline US-born & 279/250 825 & 11.1 & $0.81(0.69-0.96)$ & $1.29(1.07-1.55)$ & $453 / 250825$ & 18.1 & $0.58(0.51-0.65)$ & $0.99(0.86-1.13)$ \\
\hline Foreign-born & $508 / 595680$ & 8.5 & $0.62(0.54-0.72)$ & $1.10(0.92-1.32)$ & $925 / 595680$ & 15.5 & $0.52(0.47-0.58)$ & $1.01(0.89-1.15)$ \\
\hline Mexico & $345 / 460141$ & 7.5 & $0.55(0.47-0.64)$ & $0.93(0.75-1.16)$ & $649 / 460141$ & 14.1 & $0.48(0.43-0.53)$ & $0.89(0.77-1.04)$ \\
\hline $\begin{array}{l}\text { Central/South } \\
\text { America }\end{array}$ & 160/130 579 & 12.2 & $0.89(0.73-1.08)$ & $1.47(1.17-1.85)$ & $253 / 130579$ & 19.4 & $0.65(0.56-0.75)$ & $1.12(0.94-1.32)$ \\
\hline \multicolumn{9}{|l|}{ Asian/PI } \\
\hline US-born & 26/16 886 & 15.4 & $1.12(0.75-1.68)$ & $1.18(0.79-1.77)$ & $57 / 16886$ & 33.8 & $1.14(0.87-1.50)$ & $1.11(0.84-1.46)$ \\
\hline Foreign-born & 144/115 953 & 12.4 & $0.90(0.74-1.11)$ & $0.97(0.78-1.19)$ & $383 / 115953$ & 33 & $1.12(0.98-1.27)$ & $1.07(0.93-1.22)$ \\
\hline China & $25 / 23536$ & 10.6 & $0.77(0.51-1.16)$ & $0.71(0.46-1.11)$ & 68/23536 & 28.9 & $0.98(0.76-1.25)$ & $0.79(0.61-1.03)$ \\
\hline Japan & $3 / 4646$ & 6.5 & $0.47(0.15-1.47)$ & NA & $15 / 4646$ & 32.3 & $1.09(0.65-1.82)$ & $0.84(0.48-1.45)$ \\
\hline Korea & $22 / 17766$ & 12.4 & $0.90(0.58-1.39)$ & $1.13(0.73-1.76)$ & $51 / 17766$ & 28.7 & $0.97(0.73-1.29)$ & $0.99(0.74-1.33)$ \\
\hline Philippines & 40/28 901 & 13.8 & $1.01(0.72-1.40)$ & $1.11(0.79-1.55)$ & $108 / 28901$ & 37.4 & $1.26(1.03-1.55)$ & $1.29(1.05-1.59)$ \\
\hline Vietnam & 29/16 070 & 18 & $1.31(0.89-1.93)$ & $1.22(0.81-1.84)$ & 78/16 070 & 48.5 & 1.64 (1.29-2.08) & $1.53(1.19-1.96)$ \\
\hline
\end{tabular}

$\mathrm{Cl}$, confidence interval; NA, not applicable; RR, risk ratio

a Adjusted for maternal age ( $\leq 18,19-25,26-30,31-35$, or $>35$ years), type of birth (single or twin+), parity (1, 2, 3, or $>3$ children), infant gender (male or female), year of birth (1995-2006), gestational age ( $<37$ weeks or $\geq 37$ weeks), birth weight ( $<2500,2500-4500$, or $>4500$ g), trimester start of prenatal care (no care, first, second, or third trimester), any pregnancy complication (hypertension, renal, lung, or cardiac disease, asthma, pyelonephritis, diabetes, gestational diabetes, Rh sensitivity, hemoglobinopathy, uterine bleeding, hydramnios, incomplete cervix, sexually transmitted diseases, hepatitis B, rubella, other infections, prenatal tobacco use, and large fibroids), maternal education (less than high school, high school, more than high school), insurance type (Medi-Cal, private insurance, other), and regional center. Behavioral information is presented for cases 5 years of age at evaluation; cohort is for 1995-2004 births, $N=1340850$.

Expressive language skills and socialemotional behavior assessment partially relied on caregiver report. Although the parent interview is considered to be critical given the challenges of direct observation of the child for diagnostically assessing language and behavior, ${ }^{24}$ it might be hampered by the parent's ability to understand and report such observations accurately.

\section{CONCLUSIONS}

Our results underscore the importance of ASD research in diverse racial/ethnic populations that considers nativity to inform clinical practice. Systematic exploration of risk and protective factors related to living circumstances before and after migration is sorely needed and may lead to clinical and public health interventions (ie, mental health, environmental, or dietary interventions).
Exploring infections and immunologic profiles across immigrant subgroups, their exposures to stress and environmental factors, as well as the role of acculturation and adoption of the new culture's diet may be particularly important and informative. Equally important is the need to improve quality of and access to health care for diverse populations to improve autism diagnoses and timeliness of treatment.

\section{REFERENCES}

1. Baio J. Prevalence of autism spectrum disorders-Autism and Developmental Disabilities Monitoring Network, 14 sites, United States, 2008. MMWR Surveill Summ. 2012;61 (3): $1-19$

2. Developmental Disabilities Monitoring Network Surveillance Year 2010 Principal Investigators. Prevalence of autism spectrum disorder among children aged 8 yearsAutism and Developmental Disabilities Moni-

toring Network, 11 sites, United States, 2010. MMWR Surveill Summ. 2002;2014(63 suppl 2): 1-21

3. American Psychiatric Association. Diagnostic and Statistical Manual of Mental Disorders. 4th ed, text revision. Washington, DC: American Psychiatric Association; 2000

4. Pedersen A, Pettygrove S, Meaney FJ, et al. Prevalence of autism spectrum disorders in Hispanic and non-Hispanic white children.
Pediatrics. 2012;129(3). Available at: www. pediatrics.org/cgi/content/full/129/3/e629

5. Croen LA, Grether JK, Selvin S. Descriptive epidemiology of autism in a California population: who is at risk? J Autism Dev Disord. 2002;32(3):217-224

6. Cuccaro ML, Brinkley J, Abramson RK, Hall A, Wright HH, Hussman JP, Gilbert JR, Pericak-Vance MA. Autism in African American Families: Clinical-Phenotypic Findings. 
Am J Med Genet. 2007; Part B 144B:10221026

7. Chaidez V, Hansen RL, Hertz-Picciotto I. Autism spectrum disorders in Hispanics and non-Hispanics. Autism. 2012;16(4):381-397

8. Jarquin VG, Wiggins LD, Schieve LA, Van Naarden-Braun K. Racial disparities in community identification of autism spectrum disorders over time: Metropolitan Atlanta, Georgia, 2000-2006. J Dev Behav Pediatr. 2011;32(3):179-187

9. Courchesne E, Yeung-Courchesne R, Press GA, Hesselink JR, Jernigan TL. Hypoplasia of cerebellar vermal lobules $\mathrm{VI}$ and VII in autism. N Engl J Med. 1988;318(21):1349-1354

10. Gardener H, Spiegelman D, Buka SL. Prenatal risk factors for autism: comprehensive meta-analysis. Br J Psychiatry. 2009; 195(1):7-14

11. Stoner R, Chow ML, Boyle MP, et al. Patches of disorganization in the neocortex of children with autism. N Engl J Med. 2014;370 (13):1209-1219

12. Kolevzon A, Gross R, Reichenberg A. Prenatal and perinatal risk factors for autism: a review and integration of findings. Arch Pediatr Adolesc Med. 2007;161(4):326-333

13. Hjern A. Migration and public health: health in Sweden. The National Public Health Report 2012. Chapter 13. Scand J Public Health. 2012;40(9 suppl):255-267

14. Hamilton TG, Hummer RA. Immigration and the health of U.S. black adults: does country of origin matter? Soc Sci Med 1982 2011;73(10):1551-1560

15. Urban Institute. Children of immigrants facts and figures. 2006. Available at: www. urban.org/publications/900955.html. Accessed May 8, 2013

16. Rastogi S, Johnson TD, Hoeffel EM, Drewery MPJ. The Black Population: 2010. US Census Bureau; 2011. Available at: www.census. gov/prod/cen2010/briefs/c2010br-06.pdf Accessed May 7, 2013

17. US Census Bureau. Hispanic Americans by the numbers. Available at: www.infoplease. com/spot/hhmcensus1.html. Accessed May 8, 2013

18. US Census Bureau. Los Angeles County QuickFacts. Available at: http://quickfacts. census.gov/qfd/states/06/06037.html. Accessed July 10, 2013

19. Johnson H, Cuellar Mejia M. Immigrants in California. San Francisco, CA: Public Policy Institute of California; 2013. Available at: www.ppic.org/main/publication_show.asp? $i=258$. Accessed November 25, 2012

20. Los Angeles Almanac. Language spoken at home by Los Angeles communities. 2000 Available at: www.laalmanac.com/LA/la10b. htm. Accessed July 22, 2013
21. McPartland JC, Reichow B, Volkmar FR. Sensitivity and specificity of proposed DSM5 diagnostic criteria for autism spectrum disorder. J Am Acad Child Adolesc Psychiatry. 2012;51(4):368-383

22. California Department of Developmental Services. Autism spectrum disorders changes in the California caseload, an update: June 1987-June 2007. Available at www.dds.ca.gov/Autism/Home.cfm. Accessed October 23, 2011

23. State of California Department of Developmental Services. Diagnostic information and instruments. 1986. Available at: www. dds.ca.gov/FactsStats/Diagnostic_Main.cfm. Accessed October 23, 2011

24. California Department of Developmental Services. Autism spectrum disorders: best practice guidelines for screening, diagnosis and assessment. 2002. Available at: www.dds.ca.gov/Autism/docs/ASD_Best_ Practice2002.pdf. Accessed 0ctober 23, 2011

25. US Department of Health and Human Services; Centers for Disease Control and Prevention; National Center for Chronic Disease Prevention and Health Promotion. Registry Plus, a suite of publicly available software programs for collecting and processing cancer registry data. 2010. Available at: www.cdc.gov/cancer/npcr/. Accessed November 15, 2010

26. Becerra TA, Wilhelm M, Olsen J, Cockburn M, Ritz B. Ambient air pollution and autism in Los Angeles County, California. Environ Health Perspect. 2013;121(3):380-386

27. American Psychiatric Association. Intellectual disability. 2013. Available at: www.dsm5.org/ Documents/Intellectual\%20Disability\%20Fact \%20Sheet.pdf. Accessed February 13, 2014

28. Ritz B, Wilhelm M, Hoggatt KJ, Ghosh JKC Ambient air pollution and preterm birth in the environment and pregnancy outcomes study at the University of California, Los Angeles. Am J Epidemiol. 2007;166(9):10451052

29. Gillberg C, Steffenburg S,, Börjesson B, Andersson L. Infantile autism in children of immigrant parents: a population-based study from Göteborg, Sweden. $\mathrm{Br} J$ Psychiatry. 1987;150(6):856-858

30. Keen DV, Reid FD, Arnone D. Autism, ethnicity and maternal immigration. Br J Psychiatry. 2010;196(4):274-281

31. Magnusson C, Rai D, Goodman A, et al. Migration and autism spectrum disorder population-based study. $\mathrm{Br} J$ Psychiatry. 2012;201(2):109-115

32. Barnevik-Olsson M, Gillberg C, Fernell E. Prevalence of autism in children born to Somali parents living in Sweden: a brief report. Dev Med Child Neurol. 2008;50(8): 598-601

33. Miyake K, Hirasawa T, Koide T, Kubota T. Epigenetics in autism and other neurodevelopmental diseases. Neurodegener Dis. 2012;724:91-98

34. Woods R, LaSalle JM. Epigenetic epidemiology of autism and other neurodevelopmental disorders. In: Michels KB, ed. Epigenetic Epidemiology. Netherlands: Springer Netherlands; 2012:321-342. Available at: http://link. springer.com/chapter/10.1007/978-94-0072495-2_17. Accessed May 7, 2013

35. Michalski D, Mulvey T, Kohout J. 2008 APA Survey of Psychology Health Service Providers. 2010. Available at: www.apa.org/ workforce/publications/08-hsp/index.aspx. Accessed May 22, 2013

36. Lord C, Rutter M, Goode S, et al. Autism diagnostic observation schedule: a standardized observation of communicative and social behavior. J Autism Dev Disord. 1989;19 (2): 185-212

37. Lord C, Risi S, Lambrecht L, et al. The Autism Diagnostic Observation Schedule-Generic: a standard measure of social and communication deficits associated with the spectrum of autism. J Autism Dev Disord. 2000;30 (3):205-223

38. McInnes LA, González PJ, Manghi ER, et al. A genetic study of autism in Costa Rica: multiple variables affecting IQ scores observed in a preliminary sample of autistic cases. BMC Psychiatry. 2005;5(1):1-11

39. Yeargin-Allsopp M, Rice C, Karapurkar T, Doernberg N, Boyle C, Murphy C. Prevalence of autism in a US metropolitan area. JAMA. 2003;289(1):49-55

40. Chung I. Changes in the sociocultural reality of Chinese immigrants: challenges and opportunities in help-seeking behaviour. Int J Soc Psychiatry. 2010;56(4):436-447

41. Yamashiro G, Matsuoka JK. Help-seeking among Asian and Pacific Americans: a multiperspective analysis. Soc Work. 1997;42 (2):176-186

42. Bakare M0, Munir KM. Autism spectrum disorders (ASD) in Africa: a perspective. Afr J Psychiatry (Johannesbg). 2011;14(3):208210

43. Elsabbagh M, Divan G, Koh Y-J, et al. Global prevalence of autism and other pervasive developmental disorders. Autism Res. 2012; 5(3):160-179

44. Yi Y. Children with autism on the rise in Vietnam. 2013. Available at: http://news. xinhuanet.com/english/health/2013-03/14/ c_132234027.htm. Accessed April 21, 2013

45. Smith J. Guatemala: economic migrants replace political refugees. Migration Information Source. April 1, 2006. Available 
at: www.migrationinformation.org/Profiles/ display.cfm?ID=392. Accessed April 24, 2013

46. Terrazas A. Salvadoran immigrants in the United States. Migration Information Source. January 5, 2010. Available at: www.migrationinformation.org/usfocus/display.cfm?ID=765. Accessed May 14, 2013

47. Gammage S. El Salvador: despite end to civil war, emigration continues. Migration Information Source. July 26, 2007. Available at: www.migrationinformation.org/Profiles/ display.cfm?ID=636. Accessed April 24, 2013

48. Campagna AM, Settgast AM, Walker PF, DeFor TA, Campagna EJ, Plotnikoff GA. Effect of country of origin, age, and body mass index on prevalence of vitamin D deficiency in a US immigrant and refugee population. Mayo Clin Proc. 2013;88(1):31-37

49. Pfortmueller CA, Graf F, Tabbara M, Lindner G, Zimmermann H, Exadaktylos AK. Acute health problems in African refugees: ten years' experience in a Swiss emergency department. Wien Klin Wochenschr. 2012; 124(17-18):647-652

50. Jaranson JM, Butcher J, Halcon L, et al. Somali and Oromo refugees: correlates of torture and trauma history. Am J Public Health. 2004;94(4):591-598

51. Lindert J, Ehrenstein OS von, Priebe S, Mielck A, Brähler E. Depression and anxiety in labor migrants and refugees-a systematic review and meta-analysis. Soc SCi Med 1982. 2009;69(2):246-257

52. Hinton WL, Chen YC, Du N, et al. DSM-III-R disorders in Vietnamese refugees: prevalence and correlates. J Nerv Ment Dis. 1993; 181(2):113-122

53. Wagner J, Burke G, Kuoch T, Scully M, Armeli S, Rajan TV. Trauma, healthcare access, and health outcomes among Southeast Asian refugees in Connecticut. J Immigr Minor Health. 2013;15(6):1065-1072

54. Roberts AL, Lyall K, Rich-Edwards JW, Ascherio A, Weisskopf MG. Association of maternal exposure to childhood abuse with elevated risk for autism in offspring. JAMA Psychiatry. 2013;70(5):508-515

55. Yirmiya N, Shaked M. Psychiatric disorders in parents of children with autism: a metaanalysis. J Child Psychol Psychiatry. 2005;46 (1):69-83
56. Yetley EA. Assessing the vitamin D status of the US population. Am J Clin Nutr. 2008;88 (2):558S-564S

57. Grant WB, Peiris AN. Possible role of serum 25-hydroxyvitamin $D$ in black-white health disparities in the United States. J Am Med Dir Assoc. 2010;11(9):617-628

58. Cavalli-Sforza T. Effectiveness of weekly iron-folic acid supplementation to prevent and control anemia among women of reproductive age in three Asian countries: development of the master protocol and implementation plan. Nutr Rev. 2005;63(12 pt 2):S77-S80

59. Smitasiri S, Solon FS. Implementing preventive iron-folic acid supplementation among women of reproductive age in some Western Pacific countries: possibilities and challenges. Nutr Rev. 2005;63(12 pt 2):S81S86

60. Schmidt RJ, Tancredi DJ, Ozonoff S, et al. Maternal periconceptional folic acid intake and risk of autism spectrum disorders and developmental delay in the CHARGE (CHildhood Autism Risks from Genetics and Environment) case-control study. Am J Clin Nutr. 2012;96(1):80-89

61. Surén PRC, Roth $C$, Bresnahan $M$, et al. Association between maternal use of folic acid supplements and risk of autism spectrum disorders in children. JAMA. 2013;309 (6):570-577

62. Kočovská E, Fernell E, Billstedt E, Minnis H, Gillberg C. Vitamin D and autism: clinical review. Res Dev Disabil. 2012;33(5):15411550

63. Yang Q-H, Carter HK, Mulinare J, Berry RJ, Friedman JM, Erickson JD. Race-ethnicity differences in folic acid intake in women of childbearing age in the United States after folic acid fortification: findings from the National Health and Nutrition Examination Survey, 2001-2002. Am J Clin Nutr. 2007;85(5):1409-1416

64. Skeldon R. Migration from China. J Int Aff. 1996;49(2):434

65. Ren A, Zhang L, Hao L, Li Z, Tian Y, Li Z. Comparison of blood folate levels among pregnant Chinese women in areas with high and low prevalence of neural tube defects. Public Health Nutr. 2007;10(8):762-768
66. Zerbo 0, losif A-M, Walker C, Ozonoff S, Hansen RL, Hertz-Picciotto I. Is maternal influenza or fever during pregnancy associated with autism or developmental delays? Results from the CHARGE (CHildhood Autism Risks from Genetics and Environment) study. J Autism Dev Disord. 2013;43(1):25-33

67. Atladóttir HÓ, Henriksen TB, Schendel DE, Parner ET. Autism after infection, febrile episodes, and antibiotic use during pregnancy: an exploratory study. Pediatrics. 2012;130(6). Available at: www.pediatrics. org/cgi/content/full/130/6/e1447

68. Patterson PH. Immune involvement in schizophrenia and autism: etiology, pathology and animal models. Behav Brain Res. 2009;204(2):313-321

69. Terrazas A. Filipino immigrants in the United States. Migration Information Source. April 7, 2010. Available at: http://migrationinformation.org/USfocus/display.cfm? $i d=694 \# 13$. Accessed July 22, 2013

70. Acevedo-Garcia D, Soobader M-J, Berkman LF. Low birthweight among US Hispanic/ Latino subgroups: the effect of maternal foreign-born status and education. Soc SCI Med 1982. 2007;65(12):2503-2516

71. Flores MES, Simonsen SE, Manuck TA, Dyer JM, Turok DK. The "Latina epidemiologic paradox": contrasting patterns of adverse birth outcomes in U.S.-born and foreignborn Latinas. Womens Health Issues. 2012; 22(5):e501-e507

72. Romero CX, Duke JK, Dabelea D, Romero TE, Ogden LG. Does the epidemiologic paradox hold in the presence of risk factors for low birth weight infants among Mexican-born women in Colorado? J Health Care Poor Underserved. 2012;23(2):604-614

73. Schieve LA, Boulet SL, Blumberg SJ, et al Association between parental nativity and autism spectrum disorder among US-born non-Hispanic white and Hispanic children 2007 National Survey of Children's Health. Disabil Health J. 2012;5(1):18-25

74. Croen LA, Grether JK, Hoogstrate J, Selvin S The changing prevalence of autism in California. J Autism Dev Disord. 2002;32(3):207-215

75. Lord C, Risi S, DiLavore PS, Shulman C, Thurm A, Pickles A. Autism from 2 to 9 years of age. Arch Gen Psychiatry. 2006;63(6):694-701

(Continued from first page)

FINANCIAL DISCLOSURE: The authors have indicated they have no financial relationships relevant to this article to disclose.

FUNDING: This research was sponsored by the University of California Los Angeles (UCLA) Graduate Division, the California Center for Population Research, UCLA, supported by infrastructure grant R24HD041022 from the Eunice Kennedy Shriver National Institute of Child Health and Human Development and by NIEHS of the National Institutes of Health under award number R21ES022389. Funded by the National Institutes of Health (NIH).

POTENTIAL CONFLICT OF INTEREST: The authors have indicated they have no potential conflicts of interest to disclose. 